\title{
Quality of frozen-thawed semen in brown bear is not affected by timing of glycerol addition
}

\author{
M. Alvarez-Rodríguez ${ }^{\mathrm{a}, \mathrm{b}}$, M. Alvarez ${ }^{\mathrm{a}, \mathrm{b}}, \mathrm{S}$. Gomes-Alves ${ }^{\mathrm{a}, \mathrm{b}}, \mathrm{S}$. Borragan ${ }^{\mathrm{d}}$,

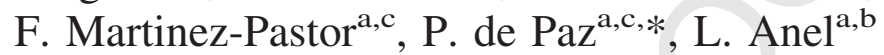 \\ a ITRA-ULE, INDEGSAL, University of León, 24071 León, Spain \\ ${ }^{\mathrm{b}}$ Animal Reproduction and Obstetrics, University of León, 24071 León, Spain \\ ${ }^{\mathrm{c}}$ Molecular Biology (Cell Biology), University of León, 24071 León, Spain \\ d Cabárceno Park, Cantabria, Spain
}

Received 10 September 2010; received in revised form 29 November 2010; accepted 6 December 2010

\section{Abstract}

We have tested several freezing protocols for brown bear semen, modifying the time when glycerol was added (before and after cooling to $5{ }^{\circ} \mathrm{C}$ ). No differences were found among protocols, indicating a good tolerance of brown bear semen to glycerol. This finding indicates that freezing protocols for brown bear semen could be modified to fit practical solutions which would facilitate preparation of the seminal samples in the field with the addition of glycerol at ambient temperature.

(C) 2010 Elsevier Inc. All rights reserved.

Keywords: Brown bear; Semen; Glycerol; Freezing

\section{Introduction}

Genome Resource Banks (GRB) are a valuable support for wild species conservation, but their application requires the optimization of cooling and freezing protocols. We are currently working on the conservation of Cantabrian brown bear (Ursus arctos) in Spain, which is seriously endangered due to habitat loss and population fragmentation, and is a suitable target for the application of GRBs [1].

One of the critical steps in the cryopreservation of a semen sample is the choice of an adequate cryoprotectant, its optimal concentration and the method of adding it during the freezing protocol to minimize the osmotic and toxic effects induced by cryoprotectant on

\footnotetext{
* Corresponding author: Tel.: +34 987291320.

E-mail address: ppazc@unileon.es (P.de Paz).
}

the cells. Glycerol has been one of the most widely applied cryoprotectant additives for mammalian spermatozoa and it has been used successfully to freeze bear spermatozoa (giant panda [2], Hokkaido brown bears [3] and Japanese black bears [4-6]). Different protocols of glycerol addition have been reported in these studies. Thus, giant panda spermatozoa were cryopreserved adding glycerol at room temperature, immediately before slow cooling [2]. Ishikawa et al [3] reported freezing semen from Hokkaido brown bears using serial dilutions, adding 1/10, 2/10, 3/10 and 4/10 of $14 \%$ extender at $4{ }^{\circ} \mathrm{C}$, achieving a final concentration of $4.7 \%$. Okano et al [4-6] cryopreserved semen from Japanese black bears at different final concentrations, diluting extended semen at $4{ }^{\circ} \mathrm{C}$, adding the same volume of extender with twice the final glycerol concentration. However, these results do not show which is the most effective method of addition in the manage- 
ment of bear semen. To our knowledge, there are no previous studies on when or the method to be used for adding glycerol to the extended semen of brown bear.

In other species, many studies have been carried out on the protocol of addition of glycerol, some concluding that glycerol should be added after cooling (4-5 ${ }^{\circ} \mathrm{C}$ ), for example in sheep [7], pig [8] and dog [9], whereas others recommend adding it at room temperature, before cooling the samples (stallion [10], red deer [11] and human [12]). Other authors have obtained the same quality regardless of when glycerol was added (stallion [13], red deer [14] and dog: [15]).

Work with endangered population often has to be carried out in the field. This includes collecting and freezing semen, therefore, the protocols are conditioned by this need. Thus, the aim of the present study was to find the most suitable protocol of glycerol addition at a final concentration of $8 \%$ for freezing brown bear semen to facilitate the preparation of the semen in the field, keeping the semen quality in these difficult conditions.

We tested three variants: 1) reaching half of the final concentration at ambient temperature, completing to final concentration after cooling to $5{ }^{\circ} \mathrm{C} ; 2$ ) adding all the glycerol at ambient temperature, reaching the final concentration [2]; and 3) adding all the glycerol after cooling to $5{ }^{\circ} \mathrm{C}$ [3-6]. Our starting hypothesis was that if the method of glycerol addition does not affect the sperm quality, it could be added at ambient temperature, thus making preparation of the seminal sample in the field easier.

\section{Materials and methods}

All the chemicals were obtained from Sigma (Madrid, Spain), except Equex STM Paste (Minitüb, Tiefenbach, Germany). Animal manipulations were performed in accordance with Spanish Animal Protection Regulation RD223/1998 (European Union Regulation 86/609).

\subsection{Animals and sample collection}

We used 17 fresh semen samples, collected from 16 adult brown bears (between 7 and 20 years old) in seventeen electroejaculation sessions, during the breeding season (late April to early July). The animals were housed in a half-freedom regimen in Cabárceno Park (Cantabria, Spain; $43^{\circ} 21^{\prime} \mathrm{N}, 3^{\circ} 50^{\prime} \mathrm{W}$, altitude: 142 metres), and fed with a varied diet.

The animals were immobilized by intramuscular administration of Zolacepan $\mathrm{HCl}$, Tiletamine $\mathrm{HCl}$
(Zoletil1001; Virbac, Carros, France) $7 \mathrm{mg} / \mathrm{kg}$ and ketamine (Imalgene 10001; Rhone-Mérieux, Lyon, France) $2 \mathrm{mg} / \mathrm{kg}$ applied by teleanaesthesia and were monitored in order to control their general status under anaesthesia. The pubic region and the penis were cleaned, the rectum was emptied of stools and the bladder was emptied by catheterization and electroejaculation was carried out with a PT Electronics electroejaculator (PT Electronics, Boring, OR, USA) using a transrectal probe $320 \mathrm{~mm}$ in length and $26 \mathrm{~mm}$ in diameter. Electric stimuli were given until ejaculation $(10 \mathrm{~V}$ and $250 \mathrm{~mA}$, in average) and ejaculates were collected in $15-\mathrm{mL}$ glass tubes at $30-32{ }^{\circ} \mathrm{C}$.

\subsection{Experimental design and semen evaluation}

Samples obtained by electroejaculation were centrifuged immediately to remove seminal plasma $(600 \times \mathrm{g}$, $6 \mathrm{~min})$. The pellet was divided in three aliquots depending on the moment of glycerol addition: PRE (before cooling to $5{ }^{\circ} \mathrm{C}$ ), POST (after cooling to 5 ${ }^{\circ} \mathrm{C}$ ) and HALF (half of the final concentration at ambient temperature, completing to final concentration after cooling to $5{ }^{\circ} \mathrm{C}$ ). First, each aliquot was diluted with the same volume of TTF extender (TESTris-Fructose $300 \mathrm{mOsm} / \mathrm{kg}, \mathrm{pH} 7.1$, with $20 \% \mathrm{egg}$ yolk, 2\% EDTA and 1\% Equex STM paste) at ambient temperature with $16 \%$ glycerol (PRE), $8 \%$ glycerol (HALF) and $0 \%$ glycerol (POST) according to treatment. The tubes with extended sample were put in glass vessels containing $100 \mathrm{~mL}$ of water at ambient temperature and transferred to a $5{ }^{\circ} \mathrm{C}$ refrigerator. After reaching $5{ }^{\circ} \mathrm{C}$, the same volume of extender was added to the POST and HALF tubes (16\% and $8 \%$ glycerol, respectively) to reach the final glycerol concentration (8\%). Final sperm concentration was achieved by adding the appropriate volume of extender to achieve a final glycerol content of $8 \%$ ). After packaging into $0.25 \mathrm{~mL}$ plastic straws, the sample is immediately cooled for $1 \mathrm{~h}$ at 5 ${ }^{\circ} \mathrm{C}$, samples were frozen in a programmable biofreezer (Kryo 560-16; PLANER plc, Sunbury, UK) at $-20{ }^{\circ} \mathrm{C} / \mathrm{min}$ down to $-100{ }^{\circ} \mathrm{C}$, and then transferred to liquid nitrogen containers. The cryopreserved samples remained in liquid nitrogen for a minimum of 1 week. Thawing was performed by plunging the straws in water at $65{ }^{\circ} \mathrm{C}$ for $6 \mathrm{~s}$. After thawing, the samples were subjected to $4 \mathrm{~h}$ incubation at $37{ }^{\circ} \mathrm{C}$. The semen samples were evaluated before freezing and after thawing (at $0 \mathrm{~h}$ and $4 \mathrm{~h}$ post-incubation to check for latent damage to the sperm).

Motility parameters were evaluated using a com- 
Table 1

Pre-freezing (PRE-F) and post-thawing parameters (Sperm motility and viability) of seventeen ejaculates from Cantabrian Brown Bears for the three groups of glycerol dilution PRE, HALF and POST (mean \pm standard error). PRE (at room temperature before refrigeration), HALF (up to half the final concentration at room temperature and the final concentration at $5{ }^{\circ} \mathrm{C}$ ) and POST $\left(5{ }^{\circ} \mathrm{C}\right.$, after refrigeration). Frozenthawed sample was assessed immediately after thawing (POST $0 \mathrm{~h}$ ) and after $4 \mathrm{~h}$ of incubation (POST $4 \mathrm{~h}$ ).

\begin{tabular}{|c|c|c|c|c|}
\hline Parameter & Sample & Post & Half & Pre \\
\hline \multirow[t]{3}{*}{$\mathrm{TM}(\%)$} & PRE-F & $77.4 \pm 3.8$ & $79.4 \pm 3.7$ & $77.4 \pm 4.1$ \\
\hline & POST $0 \mathrm{~h}$ & $53.0 \pm 3.2$ & $49.9 \pm 4.2$ & $48.0 \pm 4.4$ \\
\hline & POST $4 \mathrm{~h}$ & $27.4 \pm 7.3$ & $23.1 \pm 8.0$ & $25.6 \pm 4.8$ \\
\hline \multirow[t]{3}{*}{$\mathrm{PM}(\%)$} & PRE-F & $38.2 \pm 3.2$ & $32.8 \pm 3.6$ & $36.2 \pm 4.2$ \\
\hline & POST $0 \mathrm{~h}$ & $22.1 \pm 2.5$ & $18.0 \pm 3.3$ & $18.7 \pm 3.4$ \\
\hline & POST $4 \mathrm{~h}$ & $9.1 \pm 2.3$ & $7.8 \pm 3.0$ & $9.8 \pm 2.0$ \\
\hline \multirow[t]{3}{*}{$\operatorname{VAP}(\mu \mathrm{m} / \mathrm{s})$} & PRE-F & $77.0 \pm 2.7$ & $70.8 \pm 2.8$ & $76.6 \pm 1.8$ \\
\hline & POST $0 \mathrm{~h}$ & $63.8 \pm 2.5$ & $57.4 \pm 4.0$ & $60.3 \pm 5.2$ \\
\hline & POST $4 \mathrm{~h}$ & $30.2 \pm 3.0^{\mathrm{a}, \mathrm{b}}$ & $27.6 \pm 3.5^{\mathrm{a}, \mathrm{b}}$ & $26.5 \pm 3.4^{\mathrm{a}, \mathrm{b}}$ \\
\hline \multirow[t]{3}{*}{ LIN (\%) } & PRE-F & $46.8 \pm 2.5$ & $45.9 \pm 2.2$ & $46.8 \pm 2.1$ \\
\hline & POST $0 \mathrm{~h}$ & $37.4 \pm 0.9$ & $36.8 \pm 1.2$ & $36.0 \pm 1.4$ \\
\hline & POST $4 \mathrm{~h}$ & $31.8 \pm 1.3$ & $33.8 \pm 1.4$ & $35.8 \pm 2.6$ \\
\hline \multirow[t]{3}{*}{ iACR (\%) } & PRE-F & $74.3 \pm 5.6$ & $77.3 \pm 5.1$ & $74.3 \pm 5.3$ \\
\hline & POST $0 \mathrm{~h}$ & $62.9 \pm 3.0$ & $63.5 \pm 3.3$ & $64.2 \pm 3.4$ \\
\hline & POST $4 \mathrm{~h}$ & $49.1 \pm 8.9$ & $43.8 \pm 9.9$ & $44.9 \pm 9.7$ \\
\hline \multirow[t]{3}{*}{ dACR (\%) } & PRE-F & $3.0 \pm 0.6$ & $3.3 \pm 0.9$ & $4.2 \pm 1.1$ \\
\hline & POST $0 \mathrm{~h}$ & $10.3 \pm 2.3$ & $10.2 \pm 1.8$ & $10.5 \pm 2.1$ \\
\hline & POST $4 \mathrm{~h}$ & $19.2 \pm 3.9$ & $17.5 \pm 3.2$ & $18.8 \pm 2.9$ \\
\hline
\end{tabular}

CASA Analyses: Total motility (TM; \%), Progressive motility (PM; \%), Average velocity (VAP; $\mu \mathrm{m} / \mathrm{s})$, Linearity (LIN; \%).

Flow Cytometric Analyses: Viable spermatozoa with intact acrosomes (iACR: PNA-/PI-) and spermatozoa with damaged acrosomes (dACR: PNA+/PI- and PNA+/PI+).

${ }^{\mathrm{a}, \mathrm{b}}$ Superscript letters indicate significant differences among groups of glycerol dilution $(\mathrm{P}<0.05)$.

puter assisted sperm analysis system (CASA) (Sperm Class Analyzer; Microptic, Barcelona, Spain). Samples were diluted $\left(10-20 \times 10^{6}\right.$ cells $\left./ \mathrm{mL}\right)$ in buffered medium (HEPES $20 \mathrm{~mm} / \mathrm{L}, 197 \mathrm{mmol} / \mathrm{L} \mathrm{NaCl}, 2.5$ $\mathrm{mmol} / \mathrm{L} \mathrm{KOH}, 10 \mathrm{mmol} / \mathrm{L}$ glucose, $1 \%$ egg yolk; $\mathrm{pH} 7$; $300 \mathrm{mOsm} / \mathrm{kg}$ ), and warmed on a $37^{\circ} \mathrm{C}$ plate for $5 \mathrm{~min}$. Then, $5 \mu \mathrm{L}$ were placed in a Makler counting cell chamber (10 $\mu \mathrm{m}$ deep; Sefi Medical Instruments, Haifa, Israel). The sample was examined at $\times 10$ (negative phase contrast) in a microscope with a warmed stage $\left(38^{\circ} \mathrm{C}\right)$. The standard parameter settings were set at 25 frames/s, 20 to $90 \mu \mathrm{m}^{2}$ for head area and VCL $>10$ $\mu \mathrm{m} / \mathrm{s}$ to classify a spermatozoon as motile. At least five sequences or 200 spermatozoa were saved and analyzed afterwards.

Sperm viability and acrosomal status were assessed using the double stain PNA-FITC/PI (peanut agglutinin/propidium iodide) and flow cytometry. Sperm samples were diluted with PBS down to $5 \times 10^{6}$ spermatozoa $/ \mathrm{mL}$ in conical polypropylene tubes $(300 \mu \mathrm{L} /$ tube), staining with PI and $0.8 \mu \mathrm{g} / \mathrm{mL}$ PNA-FITC. Samples were read with a FACScalibur flow cytometer (Becton Dickinson Immunochemistry Systems, San Jose, CA, USA), equipped with standard optics and a tuned (488 mm) argon-ion laser, obtaining the percentage of viable spermatozoa with intact acrosomes (PI- and PNA-, termed iACR) and the percentage of spermatozoa with damaged acrosomes (PNA + , termed dACR).

\subsection{Statistical analysis}

Data were analyzed using SAS TM v .9.1 (SAS Institute Inc., Cary, NC, USA), by linear mixed-effects models (MIXED procedure) considering samples as a random effect. Results were expressed as the mean \pm SEM (standard error of the mean).

\section{Results and discussion}

The fresh semen samples of the brown bears studied in this experiment had a volume of $1.6 \pm 0.8 \mathrm{~mL}$ (mean \pm $\mathrm{SD})$, a pH of $8.5 \pm 0.5$, an osmotic pressure of $315.7 \pm$ 86.3 and a sperm concentration of $296.3 \pm 76.4 \times 10^{6}$ spermatozoa/mL.

Studies in dog, a carnivore like the brown bear, have indicated that glycerol should be added at $4{ }^{\circ} \mathrm{C}$ after cooling $[16,17]$. This procedure avoids the exposure of sperm to the cryoprotectant at ambient temperature, decreasing the damage sperm undergo before freezing. Conversely, Silva et al [15] concluded that glycerol could be added both at room temperature $\left(27^{\circ} \mathrm{C}\right)$ and at 
$4{ }^{\circ} \mathrm{C}$, without detrimental effects. These results are supported by studies showing that, although canine spermatozoa are sensitive to dehydration, they were able to tolerate shrinking and swelling (osmotic stress) during exposure to hypertonic solutions of glycerol [18].

The results of our study showed no significant differences between the three protocols at $0 \mathrm{~h}$, both prefreezing and post-thawing (Table 1). The incubation of the samples at $37{ }^{\circ} \mathrm{C}$ post-thawing for $4 \mathrm{~h}$ did not show any differences among protocols, except for sperm velocity (VAP), which was decreased when the final concentration of glycerol was achieved before refrigeration (PRE), in comparison with POST treatment, but no differences were observed between PRE and HALF. This finding suggests a possible negative effect of glycerol, due to a longer exposure of cells to the cryoprotectants during post-thaw incubation.

Most spermatozoa freezing protocols that have been tested for sperm of Ursidae mammalian family, glycerol has been added after cooling and thus, spermatozoa are in contact with glycerol only during the equilibration time at $4{ }^{\circ} \mathrm{C}$ [5-8]. The implications of species variability in both the beneficial and detrimental effects of glycerol are worth considering in this respect [19]. The cryoprotective action of glycerol depends on its permeability coefficient that is likely to be different among species, since it depends on the structure and composition of the membrane. No studies have been carried out to evaluate the permeability of glycerol in brown bear spermatozoa and therefore we can not assess the extent of osmotic stress in these cells. In this sense, we speculate that low VAP of spermatozoa exposed to glycerol at room temperature may be due to toxic effects rather than osmotic effects.

In conclusion, we did not detect any significant effect on sperm motility or viability in post-thawing analysis regarding the protocol of glycerol addition, suggesting that bear spermatozoa are resistant to the addition of glycerol at different temperatures. Therefore, freezing protocols for brown bear semen may be flexible in this step, which may be convenient in field conditions, when appropriate infrastructure might not be available.

\section{Acknowledgments}

This work was supported in part by CICYT (CGL 2007-63748/BOS) and CANTUR S.A.

\section{References}

[1] Anel L, Alvarez M, Martinez-Pastor F, Gomes S, Nicolas M, Mata M, Martinez AF, Borragan S, Anel E, de PP. Sperm cryopreservation in brown bear (Ursus arctos): preliminary aspects. Reprod Domest Anim 2008;43 Suppl 4:9-17.

[2] Spindler RE, Huang Y, Howard JG, Wang P, Zhang H, Zhang G, Wildt DE. Acrosomal integrity and capacitation are not influenced by sperm cryopreservation in the giant panda. Reproduction 2004;127:547-56.

[3] Ishikawa A, Matsu M, Sakamoto H, Katagiri S, Takahashi Y. Cryopreservation of the semen collected by electroejaculation from the Hokkaido brown bear (Ursus arctos yesoensis). J Vet Med Sci 2002;64:373-6.

[4] Okano T, Murase T, Tsubota T. Electroejaculation and semen cryopreservation of free-ranging Japanese black bears (Ursus thibetanus japonicus). J Vet Med Sci 2004;66[11]:1371-6.

[5] Okano T, Murase T, Yayota C, Komatsu T, Miyazawa K, Asano M, Tsubota T. Characteristics of captive Japanese black bears (Ursus thibetanus japonicus) semen collected by electroejaculation with different voltages for stimulation and frozen-thawed under different conditions. Anim Reprod Sci 2006;95:134-43.

[6] Okano T, Nakamura S, Komatsu T, Murase T, Miyazawa K, Asano M, Tsubota T. Characteristics of frozen-thawed spermatozoa cryopreserved with different concentrations of glycerol in captive Japanese black bears (Ursus thibetanus japonicus). J Vet Med Sci 2006;68[10]:1101-4.

[7] Gil J, Lundeheim N, Soderquist L, Rodriiuez-Martinez H. Influence of extender, temperature, and addition of glycerol on post-thaw sperm parameters in ram semen. Theriogenology 2003;59[5-6]:1241-55.

[8] Almlid T, Johnson LA. Effects of glycerol concentration, equilibration time and temperature of glycerol addition on post-thaw viability of boar spermatozoa frozen in straws. J Anim Sci 1988;66[11]:2899-905.

[9] Pena AI, Barrio F, Quintela LA, Herradon PG. Effect of different glycerol treatments on frozen-thawed dog sperm longevity and acrosomal integrity. Theriogenology 1998;50:163-74.

[10] Vidament M. French field results (1985-2005) on factors affecting fertility of frozen stallion semen. Anim Reprod Sci 2005;89:115-36.

[11] Fernandez-Santos MR, Esteso MC, Soler AJ, Montoro V, Garde JJ. The effects of different cryoprotectants and the temperature of addition on the survival of red deer epididymal spermatozoa. Cryo Letters 2005;26:25-32.

[12] Deppe M, Ortloff C, Salinas G, Bravo D, Sanchez R. Effect of temperature incubation and glycerol addition on the acrosome preservation in human spermatozoa. Rev Invest Clin 2004;56: 477-82.

[13] Knop K, Hoffmann N, Rath D, Sieme H. Evaluation of slow cooling after centrifugation and glycerol addition at 22 degrees $\mathrm{C}$ versus direct freezing of semen in stallions with good and poor sperm longevity. Anim Reprod Sci 2005;89:299-302.

[14] Fernandez-Santos MR, Esteso MC, Montoro V, Soler AJ, Garde JJ. Influence of various permeating cryoprotectants on freezability of Iberian red deer (Cervus elaphus hispanicus) epididymal spermatozoa: effects of concentration and temperature of addition. J Androl 2006;27:734-45.

[15] Silva AR, Cardoso RC, Silva LD. Influence of temperature during glycerol addition and post-thaw dilution on the quality of canine frozen semen. Reprod Domest Anim 2006;41:74-78. 
[18] Songsasen N, Yu I, Murton S, Paccamonti DL, Eilts BE, Godke RA, Leibo SP. Osmotic sensitivity of canine spermatozoa. Cryobiology 2002;44:79-90.

[19] Ho1t WV. Fundamenta1 aspects of sperm cryobiology: the importance of species and individual differences. Theriogenology 2000;53:47-58.
202

203

204

205

206

207

208

209

210

211

212

213

214

215

216

217

218

219

220

221

222

223

224

225

226

227

228

229

230

231

232

233

234

235

236

237

238

239

240

241

242

243 